\title{
14. 14-MEV NEUTRON ACTIVATION ANALYSIS OF SELECTED LEG 1 CORE SAMPLES
}

\author{
Activation Analysis Research Laboratory \\ Texas A \& M University, College Station, Texas
}

\section{SAMPLE PREPARATION}

Each core sample was first crushed and mixed to permit packaging in small polyethylene vials. From each crushed core sample, two sub-samples weighing approximately 1 gram each were taken at random, weighed and placed in vials which were then heat sealed. Standards containing known amounts of oxygen, silicon, iron, magnesium, and aluminum were weighed and capsulated.

\section{ANALYTICAL PROCEDURES}

Each sample and standard was irradiated with $14 \mathrm{MeV}$ neutrons for two minutes, counted for two and ten minutes after cooling times of ten minutes and two hours, respectively. A pneumatic sample transfer system was used to carry each sample to the irradiation terminal and then to a 3 inch $\times 3$ inch sodium-iodide
(T1) detector coupled to a 400 channel pulse height analyzer for counting. A weighted least-squares computer program which utilizes the information contained in the two spectra was used to resolve the radioactivity from the activation products of silicon, aluminum, iron and magnesium and to compute the amount of each element present.

The oxygen content was determined by a separate procedure which consisted of five short irradiations and counts under standardized conditions. The observed activity was then compared to that of oxygen standards by a computer program written to accommodate these calculations.

The uncertainty in the analytical results is expressed here in relative per cent, rather than absolute per cent.

TABLE 1

Major Element Composition of Selected Core Samples from Leg $1^{\text {a }}$

\begin{tabular}{|c|c|c|c|c|c|c|c|c|}
\hline \multirow[b]{2}{*}{ Hole } & \multicolumn{3}{|c|}{ Sample Designation } & \multicolumn{5}{|c|}{$\begin{array}{c}\text { Composition, } \mathrm{Wt} \%^{\mathrm{b}} \\
\text { (Average of results on duplicate samples is reported). }\end{array}$} \\
\hline & Core & Section & $\begin{array}{l}\text { Sampled } \\
\text { at }(\mathrm{cm})\end{array}$ & 0 & $\mathrm{Si}$ & $\mathrm{Fe}$ & $\mathrm{Al}$ & $\mathrm{Mg}$ \\
\hline 1 & 1 & 1 & $80-81$ & 44.8 & 28.5 & 4.41 & 8.43 & 2.6 \\
\hline 1 & 9 & 3 & $80-81$ & 44.5 & 26.6 & 4.96 & 8.13 & 3.0 \\
\hline 3 & 9 & 6 & $82-83$ & 45.0 & 28.5 & 5.7 .3 & 9.78 & 2.7 \\
\hline 4 & 1 & 5 & $94-95$ & 45.1 & 28.7 & 7.26 & 11.0 & 1.9 \\
\hline 5 & 1 & 1 & $6-7$ & 45.3 & 29.2 & 5.67 & 10.4 & 2.0 \\
\hline 5 & 3 & 1 & $65-66$ & 47.7 & 32.7 & 5.68 & 8.85 & 1.1 \\
\hline 6 & 1 & 2 & $100-101$ & 49.7 & 27.2 & 5.79 & 11.5 & 1.5 \\
\hline 6 & 2 & 5 & $80-81$ & 48.8 & 15.6 & 6.71 & 9.25 & 2.3 \\
\hline 6 & 5 & 1 & $50-51$ & 49.3 & 14.8 & 0.92 & 1.72 & 0.4 \\
\hline 7 & 1 & 4 & $80-81$ & 49.2 & 25.9 & 6.69 & 10.6 & 1.6 \\
\hline $7 \mathrm{~A}$ & 3 & 2 & $77-78$ & 46.9 & 27.6 & 8.46 & 12.4 & 1.4 \\
\hline
\end{tabular}

